\title{
Taxonomic Study of Viridans Streptococci: Description of Streptococcus gordonii sp. nov. and Emended Descriptions of Streptococcus sanguis (White and Niven 1946), Streptococcus oralis (Bridge and Sneath 1982), and Streptococcus mitis (Andrewes and Horder 1906)
}

\author{
MOGENS KILIAN, ${ }^{1 *}$ LENA MIKKELSEN ${ }^{2}$ AND JØRGEN HENRICHSEN ${ }^{3}$ \\ Departments of Oral Biology and Oral Medicine and Diagnosis, ${ }^{2}$ Royal Dental College, DK-8000 Aarhus C, Denmark, \\ and Streptococcus Department, Statens Seruminstitut, DK 2300 Copenhagen S, Denmark ${ }^{3}$
}

\begin{abstract}
We examined a collection of 151 strains of the viridans type of streptococci, which were isolated mainly from human oral cavities and included several reference strains, in an attempt to revise and improve the taxonomy of this group of bacteria. Our examinations included determinations of a high number of biochemical and physiological characteristics and serological reactivity. The resulting data revealed several hitherto unrecognized characters of taxonomic significance, and several of the species can now be more accurately defined. A diagnostic key to the taxa is presented. Strains previously identified as Streptococcus sanguis could be divided into two clearly distinct species, Streptococcus sanguis sensu stricto (type strain, ATCC 10556) and a new species, Streptococcus gordonii (type strain, ATCC 10558). Streptococcus mitis was divided into two biovars, consisting of strains possessing group $\mathbf{O}$ antigens and strains possessing group $\mathrm{K}$ antigen. The group of strains assigned to Streptococcus anginosus was biochemically and serologically heterogeneous, but the data did not allow natural subdivisions. Based on the results of this study, emended descriptions of the species Streptococcus oralis, $S$. mitis, and $S$. sanguis are provided. The classification resulting from this study is in complete agreement with previously published genetic data.
\end{abstract}

The viridans type of streptococci encountered in oral cavities and pharynges have been curiously refractory to satisfactory classification. Although several comprehensive taxonomic studies have been performed $(3,5,8,11,22,25$, $41,42,49)$, international consensus on classification and nomenclature has not been obtained. As a consequence, several synonyms have been applied to the same organisms $(18,24,29)$. Furthermore, several of the species are genetically heterogeneous $(12,13)$. However, lack of distinguishing phenotypic traits has left these problems unsolved. There is no doubt that this situation has hampered a clear understanding of the ecology of these bacteria and of some of the molecular mechanisms involved in plaque formation on teeth.

The Approved Lists of Bacterial Names published in 1980 (43) included, in addition to some of the "mutans" species, the following six species of streptococci normally encountered in oral cavities: Streptococcus sanguis, Streptococcus mitis, Streptococcus salivarius, Streptococcus anginosus, Streptococcus constellatus, and Streptococcus intermedius. Subsequently, Coykendall et al. (14) demonstrated that the last two names, together with the name "Streptococcus milleri," which is used mainly in European laboratories, are later synonyms of $S$. anginosus. Other workers have found that $S$. constellatus is sufficiently distinct from $S$. anginosus to warrant specific recognition (26).

The name "Streptococcus mitior" has been used mainly by workers in European laboratories for streptococci that lack the ability to hydrolyze arginine and esculin and may or may not produce extracellular polysaccharide. Although an overwhelming amount of data, from studies of nucleic acid homology and base composition (13), cell wall carbohy-

\footnotetext{
* Corresponding author.
}

drates (10), biochemical and physiological characteristics (5, $11,17)$, and serology $(11,23,40,46)$, has established that polysaccharide-producing strains deserve specific recognition, these organisms have been regularly referred to, in some parts of the world, as " $S$. sanguis II"; other synonyms are "S. sanguis I:A," " $S$. sanguis biotype B," and " $S$. sanguis serotype II." In addition, Colman and Williams (11) included strains otherwise referred to as $S$. mitis in " $S$. mitior" because they considered $S$. mitis a later synonym of " $S$. mitior:" Although extensively used, the name " $S$. mitior" was not included on the Approved Lists, and no formal attempt has been made to revive it. Thus, it has no formal standing. In the meantime, a new species, Streptococcus oralis, has been described (2). Although this species appears to be heterogeneous, the type strain is a typical strain of " $S$. mitior," and the new species thus covers this taxon $(29,30)$. The species $S$. mitis formally exists, yet it is not clearly defined. The type strain, which was chosen for the purpose of representing the species on the Approved Lists, does not fit the authentic description of the species (1) and is reminiscent of $S$. sanguis $(29,47)$. Recently, Whiley and Hardie described a new species, Streptococcus vestibularis, which resembles $S$. salivarius phenotypically but differs from it as determined by deoxyribonucleic acid (DNA)-DNA homology and cell wall analyses (48).

Several extensive serological studies of oral streptococci have been performed $(7,11,22,23,39,40,46)$. However, partly as a result of the above-mentioned situation, a clear correlation with the existing classification has not been achieved. This problem is further amplified by a lack of international consensus concerning reference strains for serology. The special problems concerning serological group $\mathrm{H}$ have been extensively discussed and elucidated by Cole et al. (7). 
The taxonomic study described in this paper encompassed 151 viridans streptococci, including reference strains and freshly isolated strains from oral cavities, from pharynges, and from cases of subacute bacterial endocarditis. The strains were subjected to extensive analysis by using both serology and biochemical tests, many of which were new to this group of bacteria. Most of the taxa revealed by our results were clearly defined. On the basis of these results, a new species is described, and emended descriptions of the species $S$. sanguis, $S$. oralis, and $S$. mitis are presented.

\section{MATERIALS AND METHODS}

Streptococcal strains. The designations, sources, taxonomic status, and other pertinent information on the 151 streptococcal strains used in this study are shown in Table 1. All of the strains were gram-positive, catalase-negative cocci with a tendency to form chains in broth cultures, and they lacked soluble hemolysin. Upon isolation or receipt they were subcultured on Todd-Hewitt agar (Difco Laboratories, Detroit, Mich.) plates 5 to 10 times to ensure purity and were subsequently lyophilized. A code number (beginning with the prefix SK) was assigned to each strain of the collection. Table 1 lists the strains under the taxa to which they were assigned as a result of this study.

Standard cultural conditions. Stock agar plate cultures and cultures for tests performed on agar plates were incubated at $36^{\circ} \mathrm{C}$ in a $5 \% \mathrm{CO}_{2}-95 \% \mathrm{~N}_{2}$ atmosphere obtained in anaerobic jars. All liquid cultures were incubated at $36^{\circ} \mathrm{C}$ in air. The standard inoculum used for liquid cultures was 1 drop of a 24-h Todd-Hewitt broth culture.

Colonial and cell morphology. Strains grown on mitis salivarius agar (Difco) were examined for colonial features after incubation for $24 \mathrm{~h}$ at $36^{\circ} \mathrm{C}$ in $\mathrm{CO}_{2}-\mathrm{N}_{2}$, followed by incubation for $24 \mathrm{~h}$ at room temperature in air. Overnight cultures in Todd-Hewitt broth were examined by phasecontrast microscopy, and the approximate lengths of chains were recorded.

Action on blood. Hemolysis was demonstrated on $5 \%$ horse blood agar, and greening was recorded on chocolate agar prepared with $5 \%$ horse blood.

Susceptibility tests. Susceptibility to antibiotics was examined on blood agar plates (Difco) supplemented with $5 \%$ horse blood. The plates were inoculated to give a dense growth of discrete colonies. Bacitracin disks were prepared to contain $0.05 \mathrm{U}$ per disk. In addition, sulfafurazole and nitrofurazon disks (Neo-Sensitabs; Rosco, Copenhagen, Denmark) were used. For bacitracin a zone of inhibition indicated susceptibility, as described by Facklam (17). The inhibition zones around sulfafurazole and nitrofurazon disks were measured; zone diameters of more than 22 and $14 \mathrm{~mm}$, respectively, were considered indicative of susceptibility according to the instructions of the manufacturer of the disks.

The ability to grow in broth containing 4 or $6.5 \% \mathrm{NaCl}$ (4) was recorded after incubation for 7 days.

Biochemical tests. Production of acids from carbohydrates was determined in phenol red broth base (Difco) containing $0.05 \%$ Tween 80 (16) and carbohydrates at concentrations of 1\%. Carbohydrates were added to the autoclaved medium after cooling as filter-sterilized concentrated solutions. The final $\mathrm{pH}$ was recorded with a $\mathrm{pH}$ meter (Radiometer, Copenhagen, Denmark) after incubation for 7 days. The following carbohydrates were used: glycerol, ribose, galactose, D(+)-glucose, D-(-)-fructose, D-(-)-mannose, L-(-)-sorbose, rhamnose, dulcitol, mannitol, sorbitol, $N$-acetylglucosamine, amygdalin, arbutin, esculin, salicin, D-(+)-cellobiose, maltose, lactose, D-(+)-melibiose, sucrose, D- $(+)$-trehalose, inulin, D-(+)-melizitose, D-(+)-raffinose, and soluble starch. The carbohydrates were analytical grade and were purchased from BDH, Poole, United Kingdom, E. Merck AG, Darmstadt, Federal Republic of Germany, Sigma Chemical Co., St. Louis, Mo., and Koch-Light, Colnbrook, United Kingdom.

The presence of a number of glycoside hydrolases, peptidases, phosphatases, esterases, and lipases was demonstrated by using chromogenic substrates included in two separate kits, an API ZYM kit and an API ZYM osidase kit (API System, La Balme-Les-Grottes, France). Both sets of test preparations were inoculated and read as described by the manufacturer. The bacteria used were harvested from a 24-h Todd-Hewitt broth culture and were suspended (turbidity, between MacFarland standards 5 and 6) in distilled water for the API ZYM tests and in $0.15 \mathrm{M}$ phosphate buffer $(\mathrm{pH}$ 7.5) containing $0.85 \%$ (wt/vol) $\mathrm{NaCl}$ for the API ZYM osidase tests.

Esculin hydrolysis was detected by the presence of dark coloration after 7-days of growth in a 1\% (wt/vol) Trypticasebased medium containing $0.5 \%(\mathrm{wt} / \mathrm{vol})$ yeast extract, $0.05 \%$ (wt/vol) ferric citrate, $0.5 \%$ (wt/vol) sodium chloride, and $0.1 \%$ (wt/vol) esculin (4). D-Arginine hydrolysis was tested with the Nessler reagent to detect ammonia after 5 days (11). Starch hydrolysis was detected on Todd-Hewitt broth supplemented with agar and $1 \%(w t / v o l)$ starch. After incubation, the cultures were flooded with an iodine solution. Clear zones around colonies were considered to be indicative of starch hydrolysis. Hippurate hydrolysis was demonstrated as described by Carlsson (5), and decarboxylation of ornithine and lysine was determined as described by Møller (35). Production of the extracellular polysaccharides dextran and levan from sucrose was tested by precipitation; 1 and 3 parts of $96 \%$ ethanol, respectively, were added to the supernatants of 7-day cultures in Trypticase medium containing 5\% sucrose (19).

Urease activity was detected by a micromethod (32). Production of acetoin from glucose (Voges-Proskauer test) was demonstrated in a medium composed of $1 \%$ tryptone, $0.5 \%$ yeast extract, $0.5 \%$ potassium hydrogen phosphate, and $0.5 \%$ glucose (added as a filter-sterilized solution after autoclaving) ( $\mathrm{pH}$ 7.3). A 2-ml portion of the medium was inoculated, and the culture was incubated for 4 days. Acetoin was demonstrated by using a standard procedure (17). Production of hydrogen peroxide was detected on the medium described by Müller (36).

Immunoglobulin A1 (IgA1) protease activity was demonstrated as described previously by using purified human myeloma IgA1 as the substrate (27). Neuraminidase was detected by using 4-methylumbilliferyl- $\alpha-\mathrm{D}-N$-acetylneuraminate as the substrate at a concentration of $0.1 \mathrm{mM}$ dissolved in $0.1 \mathrm{M}$ sodium cacodylate buffer ( $\mathrm{pH}$ 6.0) (44). One loopful of bacteria from a Todd-Hewitt agar plate culture was suspended in $0.2 \mathrm{ml}$ of the substrate solution, and the preparation was incubated overnight at $36^{\circ} \mathrm{C}$. After centrifugation, $0.1 \mathrm{ml}$ of the supernatant was mixed with $1 \mathrm{ml}$ of 0.1 $M$ sodium bicarbonate buffer ( $\mathrm{pH} 9.1$ ). Release of the fluorescent product was demonstrated with a fluorescence spectrophotometer (excitation, $365 \mathrm{~nm}$; emission, $450 \mathrm{~nm}$ ).

Serological examinations. The streptococcal antisera were prepared at the Streptococcus Department, Statens Seruminstitut, Copenhagen, Denmark. Grouping antisera covering groups $\mathrm{A}$ through $\mathrm{V}$, as well as antisera against " $S$. milleri," "S. mitior," Streptococcus mutans, and S. salivar- 
TABLE 1. Strains studied, listed according to the classification resulting from this study

\begin{tabular}{|c|c|c|c|c|c|}
\hline Study reference no. & Received as: & Isolated from: & $\begin{array}{l}\text { Source, strain designation(s), } \\
\text { and taxonomic status } \\
\end{array}$ & $\begin{array}{l}\mathrm{G}+\mathrm{C} \\
\text { content } \\
(\mathrm{mol} \%)^{b}\end{array}$ & $\begin{array}{l}\text { Refer- } \\
\text { ence }\end{array}$ \\
\hline \multicolumn{6}{|l|}{ S. sanguis biovar 1} \\
\hline $\mathrm{SK} 1^{\mathrm{T}}$ & S. sanguis type I & S.b.e. & $\begin{array}{l}\text { ATCC } 10556^{\mathrm{T}} \text {; type strain of } \\
\text { S. sanguis }\end{array}$ & 46 & \\
\hline SK36, SK48 & S. sanguis & Dental plaque, human & & & 27 \\
\hline SK59 & $\begin{array}{l}\text { Streptococcus sp. } \\
\text { group H }\end{array}$ & S.b.e. & NCTC $7863(=$ ATCC 10556) & 46 & \\
\hline $\begin{array}{l}\text { SK72, SK75, SK76, SK77, SK78, } \\
\text { SK85 }\end{array}$ & S. sanguis & Dental plaque, human & & & 33 \\
\hline SK104 & S. oralis & Oral cavity, human & Sneath, PB177 & & 3 \\
\hline SK108, SK118, SK119 & S. sanguis & $\begin{array}{l}\text { Initial dental plaque, } \\
\text { human }\end{array}$ & & & \\
\hline \multicolumn{6}{|l|}{ S. sanguis biovar 2} \\
\hline $\begin{array}{l}\text { SK4 } \\
\text { SK115, SK156, SK157, SK158, } \\
\text { SK164 }\end{array}$ & $\begin{array}{l}\text { Streptococcus } \mathrm{sp} \text {. } \\
\text { S. sanguis }\end{array}$ & Dental plaque, human & Carisson, 804 & & 33 \\
\hline \multicolumn{6}{|l|}{ S. sanguis biovar 3} \\
\hline $\begin{array}{l}\text { SK150, SK159, SK160, SK161, } \\
\text { SK162, SK163 }\end{array}$ & S. sanguis & $\begin{array}{l}\text { Initial dental plaque, } \\
\text { human }\end{array}$ & Nyvad & & 37 \\
\hline \multicolumn{6}{|l|}{ S. sanguis biovar 4} \\
\hline SK45, SK49, SK80 & S. sanguis & Dental plaque, human & & & 27 \\
\hline SK46 & S. sanguis & Buccal mucosa, human & & & 27 \\
\hline SK112 & $S$. sanguis & Dental plaque, human & & & 33 \\
\hline \multicolumn{6}{|l|}{ S. gordonii sp. nov. biovar 1} \\
\hline SK6 & & Lancefield group $\mathrm{H}$ & $\begin{array}{l}\text { ATCC } 12396 \text { (Lancefield F90A, } \\
\text { Hare strain Perryer) }\end{array}$ & 42 & \\
\hline SK120, SK121 & S. oralis & & $\begin{array}{l}\text { Sneath, PB179 (SK121 is a co- } \\
\text { lonial variant of SK120) }\end{array}$ & & 3 \\
\hline SK123 & Streptococcus sp. & Oral cavity, human & Our isolate & & \\
\hline \multicolumn{6}{|l|}{ S. gordonii sp. nov. biovar 2} \\
\hline SK3 ${ }^{\mathrm{T}}$ & S. sanguis type I-II & S.b.e. & $\begin{array}{l}\text { ATCC } 10558^{\mathrm{T}} ; \text { type strain of } \\
\text { S. gordonii sp. nov. }\end{array}$ & 41 & \\
\hline SK5 & $\begin{array}{l}\text { Streptococcus sp. } \\
\text { group H }\end{array}$ & & NCTC 10231 (Blackburn) & 42 & 13 \\
\hline SK 7 & $S$. sanguis & & Challis & 41 & \\
\hline SK60 & $\begin{array}{l}\text { Streptococcus sp. } \\
\text { group H }\end{array}$ & S.b.e. & NCTC 7865 (= ATCC 10558) & 41 & \\
\hline SK86 & S. sanguis & Dental plaque, human & & & 33 \\
\hline SK183 & S. sanguis & & $\begin{array}{l}\text { Burroughs Wellcome Ltd. } \\
\text { (CN2814) }\end{array}$ & & \\
\hline SK184, SK188, SK190 & S. sanguis & Dental plaque, human & Handley, FT2, MJ2, Rosan M5 & & \\
\hline \multicolumn{6}{|l|}{ S. gordonii sp. nov. biovar 3} \\
\hline SK8, SK9 & S. sanguis & Oral cavity, human & W. Liljemark (S7, S18) & & \\
\hline SK11, SK12, SK17, SK33, SK83 & S. sanguis & Oral cavity, human & Our isolates & & \\
\hline SK $51^{\mathrm{T}}$ & S. mitis & & $\begin{array}{l}\text { NCTC } 3165^{\mathrm{T}} \text {; type strain of } \\
\text { S. mitis }\end{array}$ & 39 & \\
\hline SK186 & S. sanguis & Dental plaque, human & Handley, LGR2 & & \\
\hline \multicolumn{6}{|l|}{ S. gordonii sp. nov. aberrant strains } \\
\hline SK42, SK44 & S. sanguis & $\begin{array}{l}\text { Dental plaque, Macaca } \\
\text { fascicularis }\end{array}$ & & & 27 \\
\hline SK43 & $S$. sanguis & Dental plaque, human & & & \\
\hline \multicolumn{6}{|l|}{ S. oralis } \\
\hline SK2 & S. sanguis type II & S.b.e. & ATCC 10557 (= NCTC 7864) & 42 & \\
\hline SK10 & S. sanguis type II & S.b.e. & NCTC $7864(=$ ATCC 10557$)$ & 42 & \\
\hline SK $23^{\mathrm{T}}$ & S. oralis & Oral cavity, human & $\begin{array}{l}\text { Sneath, } \mathrm{PB} 182^{\mathrm{T}}(=\mathrm{NCTC} \\
\left.11427^{\mathrm{T}}\right) ; \text { type strain of } \\
\text { S. oralis }\end{array}$ & 41 & \\
\hline $\begin{array}{l}\text { SK92, SK100, SK105, SK107, } \\
\text { SK109, SK111, SK134 }\end{array}$ & & Dental plaque, human & & & 33 \\
\hline SK122 & Streptococcus sp. & Dental plaque, human & Nyvad & & 37 \\
\hline SK133 & Streptococcus sp. I:A & Oral cavity, human & Carlsson, BU174 & 42 & 5 \\
\hline SK140 & Streptococcus sp. I:A & Oral cavity, human & Carlsson, HPA1 & 42 & 5 \\
\hline SK143 & Streptococcus sp. I:A & Oral cavity, human & Carlsson, MDP1 & 42 & 5 \\
\hline SK144 & Streptococcus sp. V:A & Oral cavity, human & Carlsson, OTF1 & 42 & 5 \\
\hline SK146 & Streptococcus sp. V:A & Oral cavity, human & Carlsson, OP51 & 42 & 5 \\
\hline SK153, SK155 & Streptococcus sp. & S.b.e. & Gutschik & & \\
\hline SK 225 & S. oralis & & DSM 20066 & 39 & 30 \\
\hline $\begin{array}{l}\text { S. oralis aberrant strains } \\
\text { SK } 38, \text { SK39 }\end{array}$ & Streptococcus sp. & Oral cavity, human & & & 27 \\
\hline
\end{tabular}


TABLE $1-$ Continued

\begin{tabular}{|c|c|c|c|c|c|}
\hline Study reference no. & Received as: & Isolated from: & $\begin{array}{l}\text { Source, strain designation(s), } \\
\text { and taxonomic status }{ }^{a}\end{array}$ & $\begin{array}{c}\mathrm{G}+\mathrm{C} \\
\text { content } \\
(\mathrm{mol} \%)^{b}\end{array}$ & $\begin{array}{c}\text { Refer- } \\
\text { ence }\end{array}$ \\
\hline \multicolumn{6}{|l|}{$S$. mitis biovar 1} \\
\hline SK24 & $\begin{array}{l}\text { Streptococcus sp. } \\
\text { group O }\end{array}$ & & NCTC 8029 & & \\
\hline SK113 & $\begin{array}{l}\text { Streptococcus sp. } \\
\text { viridans type }\end{array}$ & Sputum & NCTC 10712 (= FW75) & 40 & \\
\hline SK135 & Streptococcus sp. V:A & Oral cavity, human & Carlsson, FW103 & 40 & \\
\hline SK137, SK138, SK139, SK141 & Streptococcus sp. & Dental plaque, human & Nyvad & & 37 \\
\hline SK142 & Streptococcus sp. V:A & Oral cavity, human & $\begin{array}{l}\text { Carlsson, NS51 (= NCTC 12261); } \\
\text { proposed neotype of } S . \text { mitis }\end{array}$ & 41 & 5 \\
\hline SK145 & Streptococcus sp. V:A & Oral cavity, human & Carlsson, OS51 & 40 & 5 \\
\hline SK226 & $\begin{array}{l}\text { Streptococcus } \mathrm{sp} \text {. } \\
\text { group O }\end{array}$ & & Hahn (Kiel C119/48) & 39 & 30 \\
\hline \multicolumn{6}{|l|}{ S. mitis biovar 2} \\
\hline SK21 & Streptococcus sp. & & SSI 6235/64 & & \\
\hline $\begin{array}{l}\text { SK34, SK71, SK79, SK90, SK95, } \\
\text { SK96, SK102, SK103 }\end{array}$ & Streptococcus sp. & Oral cavity, human & Our isolates & & \\
\hline SK132 & S. mitis & Ulcerated sore throat & ATCC 903 & 39 & \\
\hline SK147, SK148, SK149 & Streptococcus sp. & Dental plaque, human & Nyvad & & 37 \\
\hline \multicolumn{6}{|l|}{ S. mitis aberrant strains } \\
\hline SK84, SK110 & & Dental plaque, human & & & 33 \\
\hline \multicolumn{6}{|l|}{ S. anginosus } \\
\hline SK14, SK47 & S. milleri & & Our isolates & & \\
\hline SK16 & S. anginosus & & HF60R & & \\
\hline SK18 & $S$. milleri & & NCTC 10708 & & \\
\hline SK19 & S. anginosus & & NCTC 8037 & & \\
\hline SK22 & S. milleri & & SSI $1986 / 64$ & & \\
\hline SK52 & S. anginosus & & $\begin{array}{l}\text { NCTC } 10713^{\mathrm{T}} \text {; type strain of } \\
\text { S. anginosus }\end{array}$ & 38 & \\
\hline SK $53^{\mathrm{T}}$ & S. constellatus & & $\begin{array}{l}\text { ATCC } 27823^{\mathrm{T}} \text {; type strain of } \\
\quad \text { S. constellatus }\end{array}$ & & \\
\hline SK5 $4^{\mathrm{T}}$ & S. intermedius & & $\begin{array}{l}\text { ATCC } 27335^{\mathrm{T}} \text {; type strain of } \\
\quad S . \text { intermedius }\end{array}$ & 38 & \\
\hline SK55 & S. oralis & & Sneath, PB183 & & \\
\hline SK57 & S. mitis & & ATCC 9895 & & \\
\hline SK61 & S. milleri & & NCTC 10709 & & \\
\hline $\begin{array}{l}\text { SK63, SK64, SK65, SK66, SK73, } \\
\text { SK81, SK87, SK88, SK89, } \\
\text { SK154 }\end{array}$ & & Dental plaque, human & & & 33 \\
\hline SK98 & S. oralis & & Sneath, PB187 & & \\
\hline SK126 & $\begin{array}{l}\text { Streptococcus sp. } \\
\text { group F }\end{array}$ & & NCTC 10714 & & \\
\hline \multicolumn{6}{|l|}{ S. salivarius } \\
\hline SK13 & S. salivarius & Human tongue & Our isolate & & \\
\hline SK25 & S. salivarius & & NCTC 8606 & 41 & \\
\hline SK26 & S. salivarius & & Kelstrup, Tove Ru & & \\
\hline SK32, SK40 & S. salivarius & Buccal mucosa, human & & & 27 \\
\hline SK $56^{\mathrm{T}}$ & S. salivarius & Cardioarthritis & $\begin{array}{l}\text { NCTC } 8618^{\mathrm{T}} \text {; type strain of } \\
\text { S. salivarius }\end{array}$ & 41 & \\
\hline SK58 & S. salivarius & & ATCC 9759 & & \\
\hline SK99, SK101 & S. salivarius & Dental plaque, human & & & 33 \\
\hline \multirow{2}{*}{\multicolumn{6}{|c|}{$S$. salivarius aberrant strains }} \\
\hline & & & & & \\
\hline SK35 & & Buccal mucosa, human & & & 27 \\
\hline SK74 & & Dental plaque, human & & & 33 \\
\hline \multicolumn{6}{|l|}{ S. mutans } \\
\hline SK27 & S. mutans & Dental plaque, human & Our isolate & & \\
\hline SK28 & S. mutans & Dental plaque, human & $\begin{array}{l}\text { NCTC } 10449^{T} \text {; type strain of } \\
\text { S. mutans }\end{array}$ & 37 & \\
\hline SK30 & S. mutans & Dental plaque, human & Gibbons, GS5 & & \\
\hline $\begin{array}{l}\text { SK62, SK68, SK69, SK70, SK91, } \\
\text { SK93, SK97 }\end{array}$ & S. mutans & Dental plaque, human & & & 33 \\
\hline
\end{tabular}

${ }^{a}$ ATCC, American Type Culture Collection, Rockville, Md.; Carlsson, J. Carlsson, University of Umea, Umea, Sweden; DSM, Deutsche Sammlung von Mikroorganismen und Zellkulturen GmbH, Braunschweig, Federal Republic of Germany; Gibbons, R. J. Gibbons, Forsyth Dental Center, Boston, Mass.; Gutschik, E. Gutschik, Department of Clinical Microbiology, Bispebjerg Hopital, Copenhagen, Denmark; Hahn, G. Hahn, Intitut für Hygiene, Kiel, Federal Republic of Germany; Handley, P. Handley, University of Manchester, Manchester, United Kindgom; Kelstrup, J. Kelstrup, Royal Dental College, Aarhus, Denmark; NCTC, National Collection of Type Cultures, Colindale, United Kingdom; Nyvad, B. Nyvad, Royal Dental College, Aarhus, Denmark; Sneath, P. H. A. Sneath, University of Leicester, Leicester, United Kingdom; SSI, Streptococcal Department, Statens Seruminstitut, Copenhagen, Denmark.

${ }_{b} \mathrm{G}+\mathrm{C}$ values from references $12,13,30$, and 48 . 
TABLE 2. Streptococcal strains used for the production of antisera

\begin{tabular}{ll}
\hline \multicolumn{1}{c}{ Group, type, or species designation } & \multicolumn{1}{c}{ Strain } \\
\hline Group C & ATCC 12388 \\
Group F & SSI H127 \\
Group G & ATCC 12394 \\
Ottens type II & H189 \\
Ottens type III & MG216 \\
Group H & Blackburn (= SK5) \\
Group H (F90A; American group H) & ATCC 12396 (= SK6) \\
" $S$. mitior" & ATCC 10557 (= SK2) \\
Group K (Levy) & NCTC 10232 \\
Group K & CN477 \\
Group O & 2/65 Jelinkova \\
"S. milleri" & SSI 14132/70 \\
"S. milleri" & SSI MG2 1132 \\
$S$. mutans type c & NCTC 10449 \\
$S$. salivarius & ATCC 13419 \\
$S$. salivarius & NCTC 8606 \\
\hline
\end{tabular}

ius and antisera against the five Ottens-Winkler antigens, were used to examine each strain (38). Those antisera that gave positive reactions with the strains which we studied are shown in Table 2; the labels of the sera are listed together with the designations of the strains used for immunization.

Antisera were prepared by immunizing rabbits with streptococci grown in Todd-Hewitt broth for about $18 \mathrm{~h}$ at $36^{\circ} \mathrm{C}$. The cultures were killed by heating them at $60^{\circ} \mathrm{C}$ for $30 \mathrm{~min}$, washed three times in saline, and stored in saline at a concentration of $1: 100$ of the original volume, with $0.5 \%$ Formalin added as preservative. The concentration of bacteria used for immunization was either $4 \times 10^{9}$ or $8 \times 10^{9}$ organisms per $\mathrm{ml}$, and the course of immunization was either 4 weeks or 2 to 3 weeks, respectively. The animals were given three successive injections of $0.5 \mathrm{ml}$ the first week and three injections of $1 \mathrm{ml}$ the following weeks. The animals were not bled until a strong capillary precipitation reaction had developed. Bleeding generally took place 5 to 6 days after the last injection.

\section{RESULTS}

Cultures. During the initial phases of this study, it became evident that many of the cultures examined yielded biochemical reactivity patterns that appeared to be intermediate between the patterns shown by defined taxa. Repeated attempts to check the purity of such cultures by serial subcultivation revealed that two different strains could be isolated only after up to five subcultures on Todd-Hewitt agar. Thus, several cultures, including "strains" received from other laboratories, initially consisted of two different strains. Consequently, all of the strains included in the study were purified by at least five serial subcultures on ToddHewitt agar.

Even after careful purification, cultures on Todd-Hewitt agar often showed a mixture of colony types that could not be separated by subculturing; i.e., they were not stable. Biochemical examination of individual cultures based on different colony types revealed identical results.

No distinct colonial morphology on Todd-Hewitt agar could be associated with the individual taxa in this study. However, in most cases, species-associated differences in colonial morphology on mitis salivarius agar were evident (Table 3).
Biochemical tests. In a pilot experiment, 18 strains that were later assigned to $S$. sanguis were tested for the ability to hydrolyze esculin both in the medium described above and in a medium in which tryptic soy broth was substituted for Trypticase peptone. While 12 of the strains showed a positive reaction in the medium containing Trypticase peptone, only 3 strains were positive in the medium containing tryptic soy broth. In the final examination of strains the medium containing Trypticase peptone was used.

Several glycoside hydrolases were determined by both the API ZYM and API ZYM osidase kits. However, as shown in Table 3, the two kits did not produce identical results. For example, the majority of the $S$. sanguis strains were recorded as negative for $\beta$-D-glucosidase and $\beta$-D-galactosidase activities when they were examined by using the API ZYM kit, whereas the majority of strains were positive when they were examined by using the API ZYM osidase kit (Table 3). Furthermore, in several cases in which the API ZYM kit yielded weak and often poorly reproducible reactions (e.g., $\alpha$-D-galactosidase), the reactions obtained with the API ZYM osidase kit were generally strong and produced more consistent results within the individual taxa.

Generally weak, indistinct, and poorly reproducible reactions were observed in the tests for esterase (API ZYM kit), esterase lipase (API ZYM kit), cystine aminopeptidase (API ZYM kit), trypsin (API ZYM kit), PNP- $\beta$-D-galacturonohydrolase (API ZYM osidase kit), and $\alpha$-L-arabinosidase (API ZYM osidase kit). These reactions are not included in the tables.

None of the strains included in the study were inhibited by optochin, had detectable lysine or ornithine decarboxylase activity, fermented glycerol, dulcitol, L-(-)-sorbose, or rhamnose, or exhibited $\alpha$-mannosidase, $\alpha$ - or $\beta$-xylosidase, $N$-acetyl- $\alpha$-D-glucosaminidase, $\alpha$-fucosidase (API ZYM kit), or $\beta$-L-fucosidase (API ZYM osidase kit) activity. All of the strains fermented D-(+)-glucose, D-(-)-fructose, and D-(-)mannose.

The $\mathrm{pH}$ values of uninoculated fermentation media were 7.2 to 7.4. When tests were recorded as positive, the final $\mathrm{pH}$ values ranged from 4.0 to 5.0 , although occasional strains showed final $\mathrm{pH}$ values for single carbohydrates of 5.6 to 5.9. Exceptions to this pattern were strains assigned to $S$. oralis, which consistently produced final $\mathrm{pH}$ values of 5.6 to 6.2 in the melibiose medium. Strains assigned to other species which were recorded as positive in this medium produced final $\mathrm{pH}$ values of 4.3 to 5.2. The final $\mathrm{pH}$ values measured in glucose broth were very consistent within individual species, with deviations of only $\pm 0.2 \mathrm{U}$ from the calculated mean (Table 3).

Characteristics of the individual taxa. The biochemical and serological characteristics of the strains which we classified are shown in Table 3. To calculate the data in the table, strains examined in duplicate that were obtained from two different sources (American Type Culture Collection, Rockville, Md., and National Collection of Type Cultures, Central Public Health Laboratory, London, England) were included only once as the duplicates always gave identical results. Strains that we considered aberrant are not included in Table 3 but are discussed individually below. The results in Table 3 are presented according to the revised classification resulting from this study. Although the names used in the tables and in the descriptions of taxa below to some extent anticipate the final taxonomic discussion (and one case is pending the response of the Judicial Commission to our proposed rejection of the present type strain of $S$. mitis [28]), it makes the presentation easier to follow. 


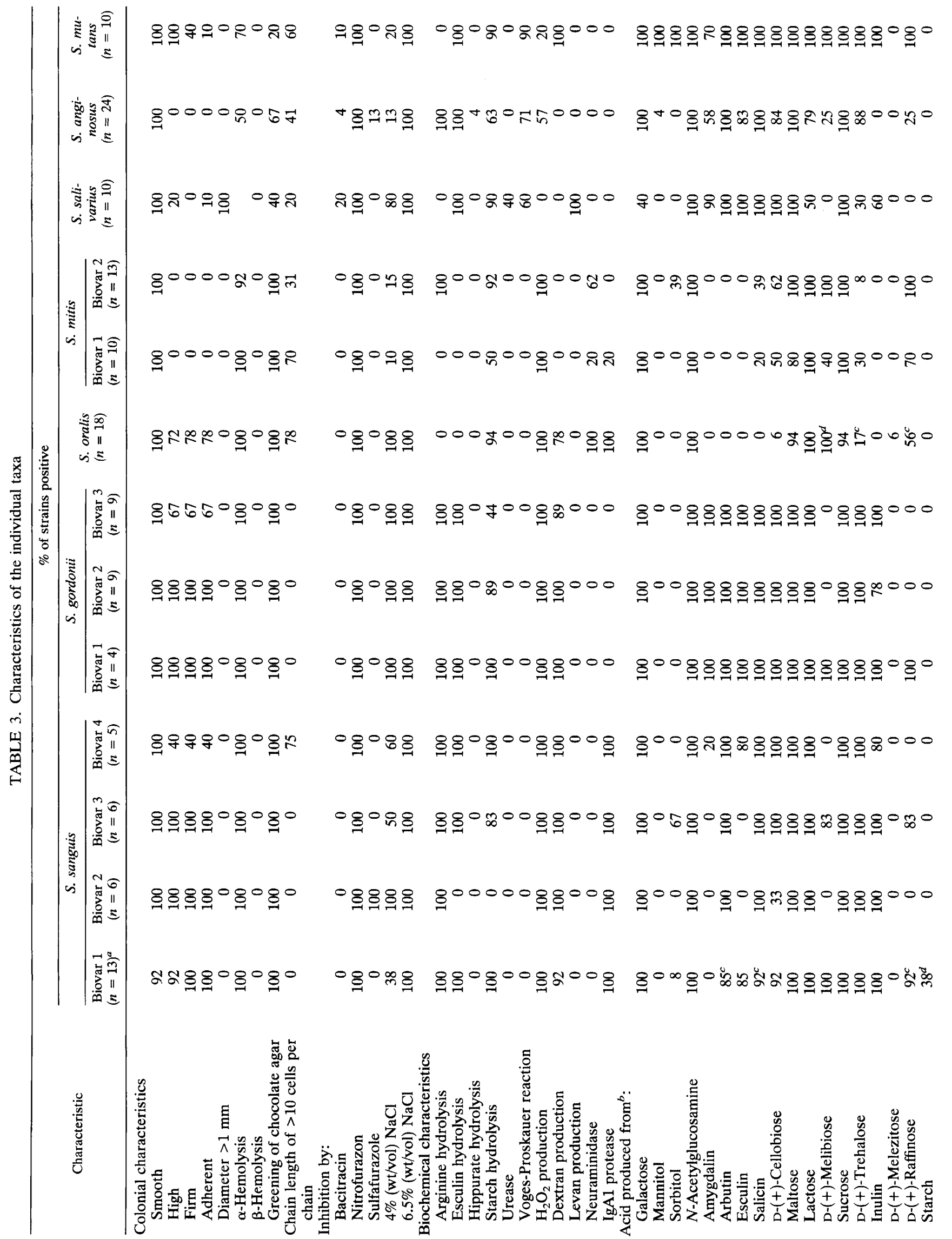




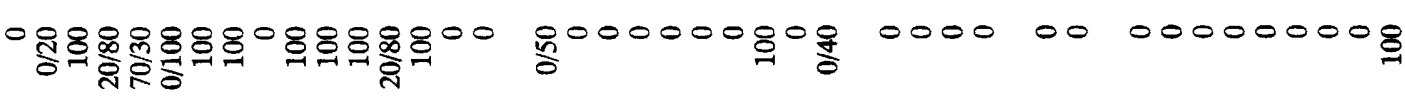

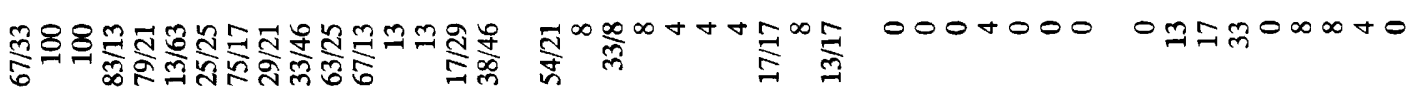

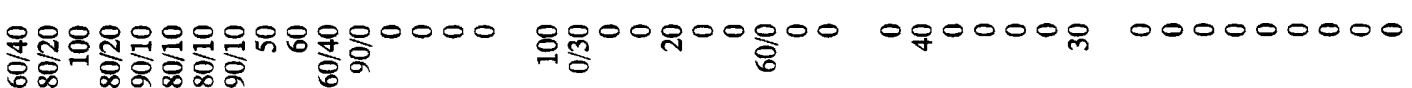

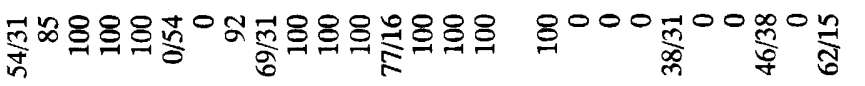
0000 min 000000000 8R8유.

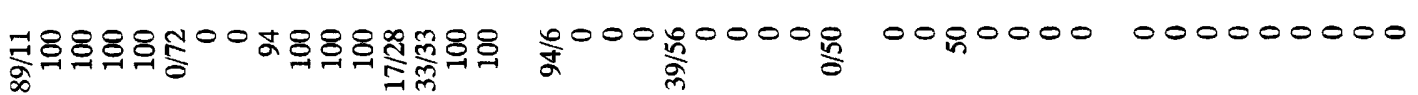
8유.

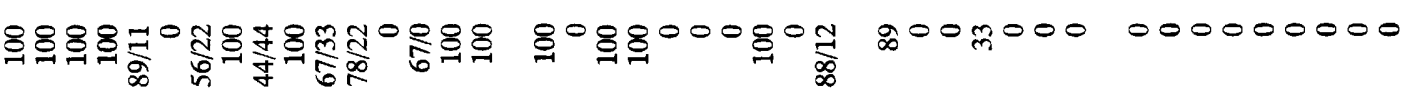

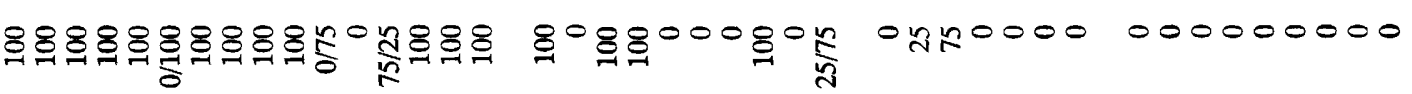

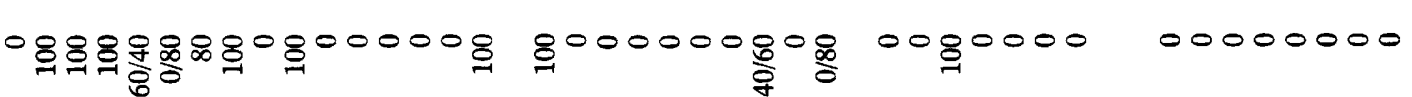

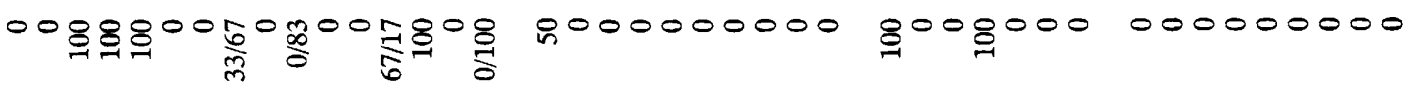
$008 \infty 8008080080080000000000000000000000000$

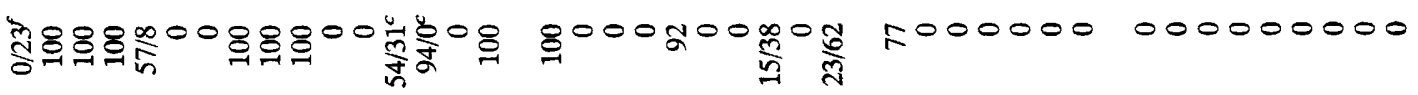

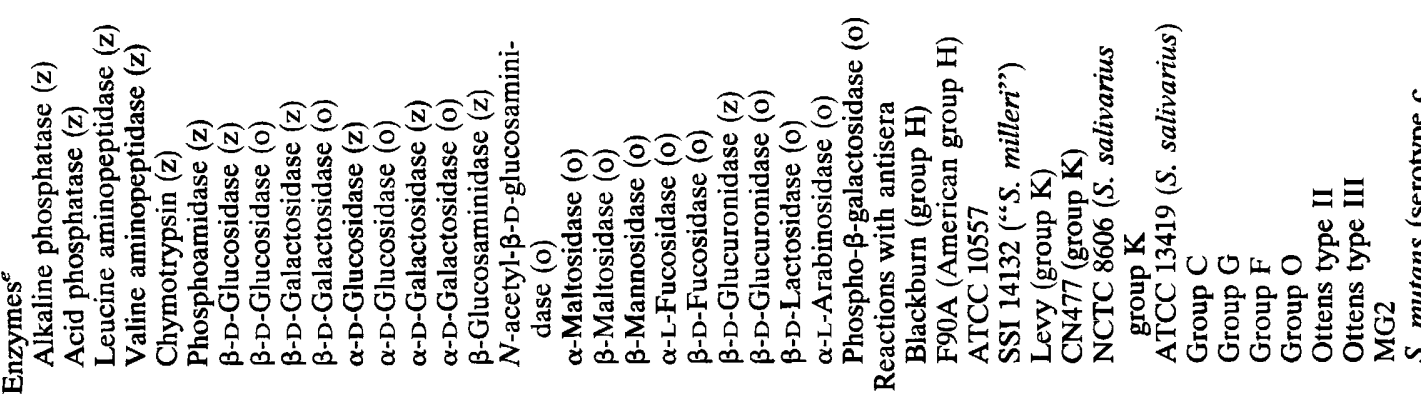


S. sanguis. A total of 31 strains were assigned to $S$. sanguis. On the basis of biochemical and serological differences, this species could be subdivided into four biovars, which are characterized as shown in Table 3. Biovar 1 included the type strain of $S$. sanguis, strain ATCC 10556 (= NCTC 7863). However, as shown in Table 3, the characteristics of the type strain differed in several ways from the majority reactions of the taxon. Only 1 of the 31 strains assigned to $S$. sanguis failed to produce detectable extracellular polysaccharide in $5 \%$ sucrose broth. This strain, strain SK118, also differed from other strains assigned to biovar 1 by fermenting sorbitol but not esculin.

With the exception of three strains of biovar 1 and five strains of biovar 4, all of the strains assigned to $S$. sanguis, including the aberrant strain, reacted with group $\mathrm{H}$ (Blackburn) antiserum. All five biovar 4 strains reacted with the antiserum against " $S$. mitior" ATCC 10557. Besides reacting with the group $\mathrm{H}$ (Blackburn) antiserum, the majority of the strains assigned to biovars 2 and 3 reacted with " $S$. milleri" SSI 14132/70 antiserum.

Streptococcus gordonii sp. nov. The 25 strains assigned to Streptococcus gordonii sp. nov. possessed many of the properties that are considered characteristic of $S$. sanguis, such as the ability to hydrolyze arginine and esculin and the ability to produce extracellular polysaccharide. However, they differed from $S$. sanguis strains in lacking $\operatorname{IgAl}$ protease activity, in their ability to ferment amygdalin, and in having $\beta$-glucosaminidase, $\beta$-mannosidase, $\alpha$-L-fucosidase, and strong alkaline phosphatase activities (Table 3). As discussed below, the results of DNA base composition and DNA-DNA homology studies support the point of view that this group warrants specific taxonomic status.

$S$. gordonii could be subdivided into three biovars on the basis of the biochemical and serological reactivities of the strains (Table 3). One of these biovars (biovar 3) included the designated type strain of $S$. mitis, strain SK51 (= NCTC 3165). However, this strain differed from all of the other strains assigned to the species by lacking extracellular polysaccharide production and by exhibiting a strong $\beta$ galactosidase reaction when the API ZYM kit was used. The taxonomic problems raised by this strain are discussed below.

Eight of the nine strains of biovar 2 reacted with group $\mathrm{H}$ (Blackburn) antiserum, and three showed an additional reaction with " $S$. milleri" SSI $14132 / 70$ antiserum. With one exception, all of the other strains reacted either with the ATCC 10557 antiserum or with the American group $\mathrm{H}$ (F90A) antiserum.

Three strains (strains SK42, SK43, and SK44) were considered aberrant strains of $S$. gordonii. Two of these, strains SK42 and SK44, were isolated from dental plaque of Macaca fascicularis monkeys. These three strains differed from other strains assigned to $S$. gordonii by exhibiting $\operatorname{IgA} 1$ protease activity (except strain SK43) and by lacking $\beta$ glucosaminidase, $\beta$-mannosidase, $\alpha$ - $L$-fucosidase, and alkaline phosphatase activities. Several of these properties are characteristic of $S$. sanguis. However, strains SK42, SK43, and SK44 differed from strains of $S$. sanguis by fermenting amygdalin, by exhibiting $\beta$-D-lactosidase activity, and by lacking $\alpha$ - and $\beta$-galactosidase and acid phosphatase activities when the API ZYM kit was used. All three strains reacted in group $H$ (Blackburn) antiserum. Although these strains appeared to be phenotypically intermediate between $S$. gordonii and $S$. sanguis, a genetic analysis of one of them (strain SK42) revealed that it is closely related to the former species but not to the latter species (20).
S. oralis. A total of 21 strains were assigned to $S$. oralis. These strains included the type strain of $S$. oralis (strain NCTC 11427) and several other reference strains previously designated " $S$. sanguis II" or " $S$. mitior" (Table 1). The majority of the strains produced extracellular polysaccharide, and all exhibited both $\mathrm{IgA} 1$ protease and neuraminidase activities. A detailed description of 18 of the strains is provided in Table $3 ; 9$ of these 18 strains, including the type strain, reacted in the antiserum raised against strain ATCC 10557. The remaining strains were negative in all antisera. Two strains (strains SK38 and SK39), which were considered aberrant, differed from all of the other strains of the species by lacking $\beta$-glucosaminidase, $\beta$-galactosidase (API ZYM kit), and alkaline phosphatase activities.

S. mitis. A total of 25 strains were tentatively assigned to $S$. mitis (see below). This species was subdivided in two groups, designated biovar 1 and biovar 2 . None of the strains produced extracellular polysaccharide. The two biovars were separated by having different reactions in tests for arginine hydrolysis, $\beta$-glucosaminidase, $\beta$-glucosidase, and $\alpha$-mannosidase (Table 3 ). The detailed biochemical characteristics are shown in Table 3. Two strains tentatively assigned to biovar 1 (strains SK135 and SK136) exhibited both $\operatorname{IgA1}$ protease and neuraminidase activities.

All but one of the strains assigned to biovar 1 reacted with the group $\mathrm{O}$ antiserum, and two, in addition, reacted with the antiserum raised against $S$. salivarius NCTC 8606 . The majority of the biovar 2 strains reacted with one of the two group $\mathrm{K}$ antisera (Levy and CN477). One strain, strain SK132 (= ATCC 903), reacted with both of these antisera, as well as with the NCTC 8606 and Ottens type III antisera, and one strain reacted with the NCTC 8606 antiserum only.

The four strains assigned to biovar 2, including strain SK132 (= ATCC 903), which reacted with the CN477 group $\mathbf{K}$ antiserum, may warrant recognition as a separate biovar as they differed from other strains of biovar 2 by lacking neuraminidase and $\beta$-D-fucosidase activities and by fermenting sorbitol.

Likewise, the exact classification of two strains (strains SK84 and SK110) listed as aberrant will require further study. In contrast to the strains of biovar 2, these two strains did not hydrolyze arginine but did hydrolyze esculin and fermented trehalose. They otherwise possessed the majority of the reactions of $S$. mitis biovar 2 (Table 3), including neuraminidase activity.

$S$. salivarius. The 10 strains assigned to $S$. salivarius included the type strain of $S$. salivarius, strain NCTC 8618 (= SK56), and two other reference strains of $S$. salivarius (Table 1). This group of strains was relatively homogeneous and was well separated from the other taxa (Table 3). The majority of the strains reacted with antiserum against either American group H (F90A) or S. salivarius NCTC 8606. Two additional strains assigned to this species were considered aberrant. Strain SK35 differed from other strains in lacking the ability to ferment $N$-acetylglucosaminic acid, in fermenting melibiose and raffinose, in exhibiting a strong $\beta-D-$ fucosidase reaction, and in lacking alkaline and acid phosphatase, valine aminopeptidase, and phosphoamidase activities. It reacted with the American group H (F90A) antiserum. The other strain (strain SK74) was the only strain in the collection that was capable of hydrolyzing hippurate. Furthermore, it differed from the other strains by lacking the ability to ferment $N$-acetylglucosaminic acid, by exhibiting $\beta$-mannosidase and $\beta$-glucuronidase activities, and by lacking $\alpha$-maltosidase activity. It reacted with ATCC 13419 antiserum. 
$S$. anginosus. The 24 strains tentatively assigned to $S$. anginosus included the type strains of $S$. anginosus, $S$. constellatus, and $S$. intermedius, several reference strains of " $S$. milleri," S. mitis ATCC 9895, and two strains classified as $S$. oralis by Bridge and Sneath (3) (Table 1). All 24 strains hydrolyzed arginine and esculin, and the majority (71\%) produced acetoin. However, as revealed by the data in Table 3 , this taxon was a biochemically and serologically very heterogeneous group, and no natural clustering of the 24 strains was found. The strains were separated from strains assigned to $S$. sanguis and $S$. gordonii by their lack of extracellular polysaccharide formation, by their inability to ferment inulin, by their colonial morphology on mitis salivarius agar, and by their serological reactions. None of the strains assigned to $S$. anginosus possessed a group $\mathrm{H}$ antigen. In contrast, the majority of the strains reacted with group $\mathrm{C}, \mathrm{F}$, or $\mathrm{G}$ antiserum and with antiserum to Ottens type II or III (Table 3).

S. mutans. The 10 strains assigned to $S$. mutans formed a homogeneous group with only minor variations in certain biochemical reactions (Table 3). All of the strains reacted in serotype $\mathrm{c}$ antiserum. The strains were clearly separated from all other strains included in this study.

Genetic relatedness between and within the species. The strain collection examined in this study was composed to include, as far as possible, strains that previously had been subjected to genetic analyses, such as determinations of DNA base composition and DNA-DNA homology and multilocus enzyme analysis. As the data from these studies formed an important background for the taxonomic decisions resulting from our study, they are summarized below with special emphasis on the species $S$. oralis, $S$. mitis, $S$. sanguis, and $S$. gordonii.

Six of the strains which we assigned to $S$. oralis (strains SK2, SK133, SK140, SK143, SK144, and SK146) and three of the strains assigned to $S$. mitis (strains SK135, SK142, and SK145) were examined in DNA-DNA hybridization experiments (S1 nuclease method) by Coykendall and Munzenmaier (12). Applied to our classification, the results of these authors showed 65 to $100 \%$ homology within $S$. oralis and $S$. mitis and 30 to $38 \%$ homology between the two species. Values compatible with this level of interspecies relatedness have been reported for $S$. mitis biovar 1 (strain SK226) and $S$. oralis (strain SK23) by Kilpper-Bälz et al. (30) and for $S$. mitis biovar 2 (strain SK132) and $S$. oralis (strain SK2) by Coykendall and Specht (13).

DNA homology data demonstrating the intra- and interspecies relationships of $S$. sanguis and $S$. gordonii as defined in this study have been published for $S$. sanguis SK1, SK4, and SK59 and $S$. gordonii SK3, SK5, SK6, SK51, and SK190 by Coykendall and Specht (13), Schmidhuber et al. (41), and Welborn et al. (47). Applied to our classification, the data from these studies showed 89 to $90 \%$ genetic homology within the species and 40 to $60 \%$ homology between the two species. Furthermore, all three studies demonstrated 20 to $30 \%$ genetic homology between $S$. sanguis and $S$. gordonii on one side and $S$. oralis on the other. These levels of intra- and interspecies relatedness among the three species are further supported by the results of our own genetic analysis of 23 strains from this study in which multilocus enzyme electrophoresis was used (20).

Information on the intra- and interspecies relationships and DNA base compositions based on studies of strains included in this study is summarized in Fig. 1. DNA base compositions compiled from previous studies $(12,13,48)$ are included in Table 1 for individual strains.

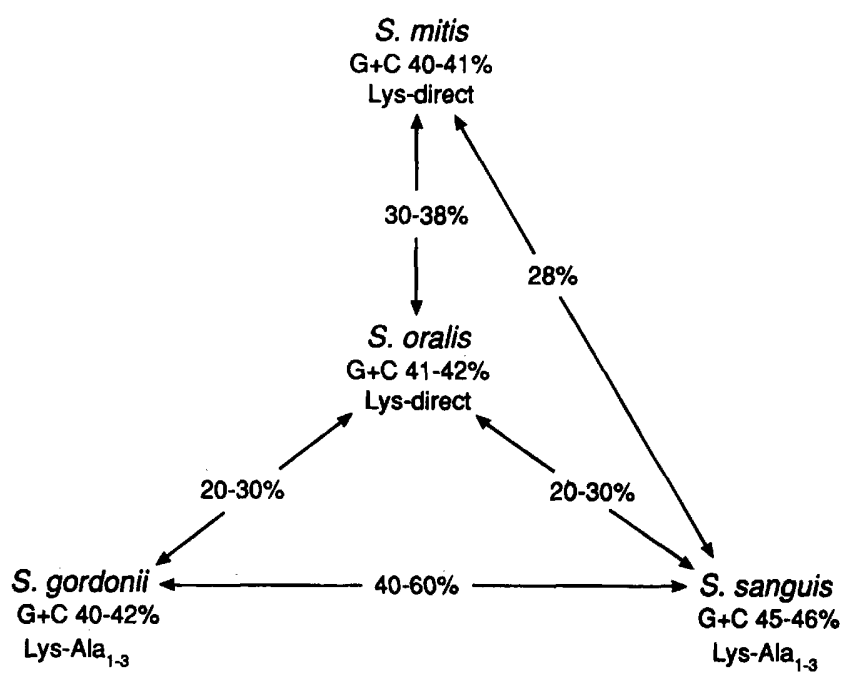

FIG. 1. Genetic relatedness, DNA base compositions, and cell wall peptidoglycan types of selected Streptococcus species defined in this study. The information is compiled from previously published data for strains included in this study $(12,13,30,41,47)$.

\section{DISCUSSION}

Several factors undoubtedly contribute to the difficulties that have been encountered in reaching a satisfactory taxonomy of oral streptococci. It is notoriously difficult to obtain pure cultures of these bacteria, as we experienced in the initial phases of this study. This has probably led several authors to consider oral streptococci a continuum with overlapping species and many intermediate forms $(15,22)$. Second, many of the biochemical tests used to examine streptococci are not sufficiently optimized for these bacteria, and small alterations in a test may give different results. This is evident when results reported by workers from different laboratories for identical strains are compared. For example, the type strain of $S$. sanguis, strain ATCC 10556 (=SK1), is often reported to be negative for esculin hydrolysis. In our study this strain was found to be clearly positive in the test substrate recommended by Carlsson (4), but negative, along with several other $S$. sanguis strains, if tryptic soy broth was substituted for Trypticase peptone in the medium. Several differences between phenotypic data reported by workers in the laboratory of Schleifer $(30,41)$, who used API 20 STREP (41) or "conventional tests" (30), also demonstrate the importance of the methods used to determine specific biochemical activities of streptococci. Thus, the type strain of $S$. sanguis, strain ATCC 10556 (= SK1), has been reported to be unable to hydrolyze arginine (30), whereas the type strain of $S$. oralis was found to be positive. Both results are in conflict with data from several other studies, including our study. Other examples, which are relevant for the phenotypic description of $S$. oralis, are discussed below.

Similar discrepancies in the reported abilities of strains to ferment carbohydrates may be due to the use of different $\mathrm{pH}$ indicators. To avoid this problem, we measured the final pH in every fermentation test culture after 7 days of incubation. Virtually all of the reactions recorded as positive reached $\mathrm{pH}$ values between 4.0 to 5.0 , and the values were remarkably consistent within each taxon (Table 3). However, a few characteristic exceptions were found. Thus, the final $\mathrm{pH}$ values of $S$. oralis strains in melibiose and of $S$. sanguis biovar 1 strains in starch were consistently between 5.6 and 6.2. 
The API kits with chromogenic substrates used to detect glycoside hydrolases in this study also demonstrate the significance of test optimization. API ZYM kits have been used previously in studies of oral and other streptococci (3, $9,45)$. However, the reproducibility and diagnostic validity of the results have not been entirely satisfactory. The same problems were observed in this study for some of the reactions. The importance of the substrate used for propagation of the inoculum has been demonstrated previously (9). Another factor is demonstrated by the results obtained in our study, in which we used two different API kits with many overlapping tests. Table 3 shows that the results obtained for identical glycoside hydrolases with the two kits often were quite different. Generally, results obtained with the API ZYM osidase kit were more clear-cut, reproducible, and consistent within individual taxa. The two kits use different chromogenic substrates (i.e., naphtol and nitrophenol derivatives, in the API ZYM and API ZYM osidase kits, respectively), which may influence the results. However, it may also be significant that the inocula used for the API ZYM osidase kit tests were suspended in a buffer at $\mathrm{pH} 7.5$, which is closer to the $\mathrm{pH}$ optimum of the relevant enzymes (pH 7.5 to 8.0) (unpublished data) than the pH obtained with the API ZYM kit tests, which used saline-suspended inocula.

Two of the tests used in this study, the $\operatorname{IgA} 1$ protease and neuraminidase tests, have not been used previously in streptococcal taxonomy. Both of these tests proved to be highly valuable in supporting the classification presented in Table 3 . However, the drawback of the two tests is that they require specialized equipment and are, at the present time, not easily applicable to routine bacteriology.

The individual taxonomic groups resulting from this study are discussed below. The entity previously referred to as " $S$. sanguis II" is a priori excluded from the discussion of $S$. sanguis as " $S$. sanguis II" strains differ from the type strain of $S$. sanguis by multiple biochemical characteristics $(5,11$, 24) (Table 3), by growth requirements (6), by cell wall composition $(10,34,39)$, by serology $(11,23)$, by DNA base composition, and by exhibiting only 20 to $40 \%$ DNA homology $(13,41)$. " $S$. sanguis II" is discussed below under $S$. oralis.

$S$. sanguis. $S$. sanguis is the name given by White and Niven (49) to the viridans type of streptococci that hydrolyze arginine, usually hydrolyze esculin, ferment inulin, salicin, lactose, and trehalose, and produce extracellular dextran from sucrose (26). However, a certain heterogeneity has been suggested as a result of both biochemical and serological studies $(29,39,49)$. Most convincingly, Coykendall and Specht (13) demonstrated two separate genotypes with only 30 to $60 \%$ DNA homology and significantly different DNA base compositions (guanine-plus-cytosine $[\mathrm{G}+\mathrm{C}]$ contents, 44 to 46 and 41 to 43 mol\%). The names " $S$. sanguis subsp. carlssonii" and "S. sanguis subsp. sanguis" were applied to the two genotypes, but because of a lack of correlating phenotypic differences this subdivision has never been practically employed. Our study revealed several phenotypic traits that clearly differentiate two major clusters, which, as noted above, contained several strains representing the genotypes described by Coykendall and Specht. The two clusters clearly warrant specific recognition (see below). The cluster that includes the type strain of $S$. sanguis, strain ATCC 10556 (= NCTC 7863) (Table 3), must retain the name $S$. sanguis. $S$. sanguis, thus defined, correlates with $S$. sanguis subsp. carlssonii of Coykendall and Specht.

$S$. sanguis sensu stricto was divided into four taxa that were separated by several biochemical and serological characteristics. We provisionally label these taxa biovars 1 through 4 . The type strain was assigned to biovar 1. Paradoxically, this strain was unique among the $S$. sanguis strains because it lacked the ability to ferment several carbohydrates typical of the species (Table 3). The majority of the $S$. sanguis strains reacted with the group H (Blackburn) antiserum. However, it is interesting that none of the strains reacted with the American group H (F90A) antiserum. The five strains assigned to biovar 4 were exceptional in reacting with antiserum against $S$. oralis ATCC 10557 (" $S$. mitior") but not with any of the group $\mathrm{H}$ antisera and by forming long chains (Table 3). Also, strains of biovar 4 have been shown to differ from other $S$. sanguis strains by possessing a distinct IgA1 protease type (Reinholdt et al., in preparation) and may belong to a separate species.

$S$. gordonii sp. nov. The cluster excluded from $S$. sanguis included strains previously designated " $S$. sanguis subsp. sanguis" by Coykendall and Specht (13). Furthermore, it contained strain NCTC 3165 (= SK51), which is the designated type strain of $S$. mitis (43). This strain differed from all other strains of $S$. gordonii by lacking detectable extracellular dextran, and we previously demonstrated a genetic distance of $20 \%$ (Gower distance coefficient) between this strain and other representative strains of $S$. gordonii based on multilocus enzyme electrophoresis (20). In our opinion, it would clearly cause confusion to apply the name $S$. mitis to this group of organisms which is characterized by arginine and esculin hydrolysis, inulin fermentation, and production of extracellular polysaccharide, and it would be in conflict with the original description of that species (1). Pending the response of the Judicial Commission to our request to replace the type strain of $S$. mitis (28), we propose the name $S$. gordonii in honor of the British bacteriologist Mervyn $\mathrm{H}$. Gordon, who apparently was the first researcher to apply fermentation tests to the classification of viridans streptococci in a comprehensive way (21). Previously published DNA-DNA hybridization data on five strains which we assigned to $S$. gordonii (see above) show that it is a homogeneous taxon. It is clearly distinct from $S$. sanguis based on the following data: it exhibits only 40 to $60 \%$ DNA homology with $S$. sanguis (Fig. 1); it has a significantly lower $\mathrm{G}+\mathrm{C}$ content than $S$. sanguis (42 versus $46 \mathrm{~mol} \%$ ) (13); it ferments amygdalin; it has alkaline phosphatase and $\beta$-glucosaminidase activities; and it lacks IgA1 protease activity (Table 3 ). Further genetic evidence to support the separation of the two species was recently obtained by a multilocus enzyme analysis of several representative strains from this study (20).

The three taxa defined within $S$. gordonii differ biochemically and serologically. Whereas the majority of strains assigned to biovars 1 and 3 reacted with the antiserum against $S$. oralis ATCC 10557 (" $S$. mitior") and some reacted with American group H (F90A) antiserum, most of the strains of biovar 2 reacted with group $H$ (Blackburn) antiserum. Together with some of our findings for group $\mathrm{K}$ strains (see below), these results confirm and extend previous observations $(7,11)$ that streptococcal group antigens may be shared by separate species. Based on results published by Rosan (40) and Cole et al. (7) for strains common to their studies and our study, it appears that $S$. gordonii biovar 2 strains contain all of the antigens (antigens a through e) defined by Rosan (40), as does the type strain of $S$. sanguis (strain ATCC 10556). S. gordonii biovar 1 strain SK6 (= F90A) was previously found to possess antigens $a$ and e, whereas $S$. gordonii biovar 3 strain SK51 (= NCTC 3165) 
was found to possess antigens a, $c$, and $d(7)$. The latter finding explains the reaction of $S$. gordonii biovar 3 strains with ATCC 10557 antiserum ( $S$. oralis/" $S$. mitior') as strain ATCC 10557 has been found to possess antigens $\mathrm{c}$ and $\mathrm{d}(7)$. According to Rosan (40), antigen a is the group $\mathrm{H}$ antigen. Thus, it appears that all $S$. gordonii biovars possess the group $\mathrm{H}$ antigen, although only biovar 2 strains reacted with the Blackburn serum.

$S$. oralis. $S$. oralis is the name applied by Bridge and Sneath (2) to one of their clusters resulting from a numerical taxonomic study of streptococci (3). As defined by these authors, this taxon appears to be heterogeneous because representative strains from their study were assigned in this study to widely different species, including $S$. oralis, $S$. sanguis, $S$. gordonii, and $S$. anginosus. The taxon resulting from our study, which included the type strain of $S$. oralis, was characterized by the production of extracellular polysaccharide by most strains, by neuraminidase and $\mathrm{IgA} 1$ protease activities, and by a lack of arginine and esculin hydrolysis and inulin fermentation; 9 of 18 strains, including the type strain, reacted with the antiserum against ATCC 10557 , which is consistent with the fact that this strain and several other strains previously referred to as " $S$. mitior" or " $S$. sanguis II" were included in the species. DNA-DNA hybridization data for six of the strains which we included in $S$. oralis (see above) confirm that this species is genetically homogeneous and well separated from other species, including $S$. mitis (Fig. 1).

Kilpper-Bälz et al. (30) have published an emended description of $S$. oralis based on data resulting from their own study and data reported by Bridge and Sneath (2). However, there are several significant discrepancies between the results of these authors and our results. Thus, both the type strain of $S$. oralis, strain NCTC 11427 (= SK23), and $S$. oralis DSM 20066 (= SK225) were found to be positive for arginine hydrolysis and acetoin production, and strain DSM 20066 was also found to be positive for esculin hydrolysis by Kilpper-Bälz et al. (30). We were unable to confirm these data, which results in $S$. oralis being phenotypically more homogeneous than reported by Kilpper-Bälz et al. (30). Furthermore, we found that none of the strains exhibits lysine decarboxylase activity as previously reported for $S$. oralis (3). On the basis of our results an emended description of $S$. oralis is presented below.

$S$. mitis. The name $S$. mitis was used by Andrewes and Horder (1) to designate streptococci which are rarely pathogenic, grow in short chains, and usually fail to ferment inulin and raffinose. Because of the lack of sufficient detail in this description, the definition of $S$. mitis is usually based on the description provided by Sherman et al. (42). Although, these authors noted that " $S$. mitis forms a rather heterogeneous and perhaps complex group," they found that it was well separated from other viridans species by the inability of any culture out of 147 studied to ferment inulin or to synthesize polysaccharide from sucrose. That the $S$. mitis group may contain more than one distinct unit was indicated by the fact that an appreciable proportion of the strains of this group hydrolyzed arginine with the production of ammonia (42). These characteristics concur with the definition of $S$. mitis used by Carlsson (5), Facklam (17), and workers in several other laboratories.

The use of the name $S$. mitis for the two clusters defined in Table 3 is in complete agreement with the definitions used by Sherman et al. (42), Carlsson (5), and Facklam (17). However, the formal acceptability of this name is pending the response of the Judicial Commission to our request to reject the present type strain of S. mitis, strain NCTC 3165 (= SK51) (28); we propose to replace this strain with strain NCTC 12261.

$S$. oralis and $S$. mitis, as defined here, are related by having a cell wall composition that is distinct from that of $S$. sanguis. In contrast to $S$. sanguis, the cell walls of $S$. oralis and $S$. mitis (biovars 1 and 2) lack glycerol teichoic acid and significant amounts of rhamnose and contain a ribitol teichoic acid $(10,11,33,39)$. Accordingly, $S$. oralis and $S$. mitis were grouped together as " $S$. mitior" by Colman and Williams (11); however, the subsequent study of Coykendall and Munzenmaier (12), which included several strains which we classified as $S$. oralis and $S$. mitis, respectively, demonstrated that these two species exhibit only 40 to $60 \%$ DNA homology. As demonstrated in Table 3, the two species are also well separated by biochemical and serological differences and furthermore have different ecological properties (Kilian, manuscript in preparation). As the study of Coykendall and Munzenmaier (12) did not contain representatives of $S$. mitis biovar 2, further studies will be required to define definitively the correct affiliation of this taxon.

$S$. anginosus. The taxon that contained the type strain of $S$. anginosus also encompassed the type strains of $S$. intermedius and $S$. constellatus and several strains labeled " $S$. milleri." The 24 strains formed a phenotypically heterogeneous group, and no natural subdivisions were possible on the basis of the data. This finding confirms conclusions from several previous studies that many strains of $S$. anginosus, $S$. constellatus, and $S$. intermedius are closely related to each other genetically in spite of phenotypic heterogeneity $(14,31,46)$. Therefore, we followed the recent proposal by Coykendall et al. (14) to use the designation $S$. anginosus for the whole group of bacteria because of the priority of that name. In the present study $S$. anginosus could be separated from $S$. sanguis by a lack of extracellular polysaccharide and IgA1 protease activity, by differences in colonial morphology, by the inability to ferment inulin, by a positive VogesProskauer reaction in most strains, and by serological reactivity (Table 3 ). Clearly, further studies will be required to explain the taxonomically unnatural situation surrounding this group of bacteria.

$S$. salivarius. The taxon that contained the type strain of $S$. salivarius formed a relatively homogeneous group which was well separated from other species. The 10 strains possessed the typical characteristics of $S$. salivarius, including extracellular levan production. Thus, none of the strains appears to be related to the newly described species $S$. vestibularis (48).

$S$. mutans. The 10 strains assigned to $S$. mutans included the type strain and pose no taxonomic problems. Strains of other mutans species were not included in the study.

Table 4 lists the phenotypic characteristics that are most useful for distinguishing the streptococcal species and their biovars as defined here. The characteristics included in this table are those that were found to be constant and most reproducible in tests.

Table 5 correlates the classification presented here with designations used previously in the literature. This table is based on previously published information concerning reference strains common to the individual studies.

Description of Streptococcus gordonii sp. nov. Cells are gram-positive cocci that grow in short chains in serum broth. They are nonmotile, nonsporing, aerobic and facultatively anaerobic, fermentative, and catalase negative and show $\alpha$-hemolysis on horse blood agar and pronounced greening on chocolate agar. The cell wall contains glycerol teichoic 
TABLE 4. Differential characteristics of the species

\begin{tabular}{|c|c|c|c|c|c|c|c|c|c|c|c|c|c|}
\hline \multirow{2}{*}{ Characteristic } & \multicolumn{4}{|c|}{ S. sanguis } & \multicolumn{3}{|c|}{ S. gordonii } & \multirow{2}{*}{ S. oralis } & \multicolumn{2}{|c|}{ S. mitis } & \multirow{2}{*}{$\underset{\text { salivarius }}{S .}$} & \multirow{2}{*}{$\begin{array}{c}S . \\
\text { anginosus }\end{array}$} & \multirow{2}{*}{$\begin{array}{c}S . \\
\text { mutans }\end{array}$} \\
\hline & $\begin{array}{c}\text { Biovar } \\
1\end{array}$ & $\begin{array}{l}\text { Biovar } \\
2\end{array}$ & $\begin{array}{l}\text { Biovar } \\
3\end{array}$ & $\begin{array}{c}\text { Biovar } \\
4\end{array}$ & $\begin{array}{c}\text { Biovar } \\
1\end{array}$ & $\begin{array}{l}\text { Biovar } \\
2\end{array}$ & $\begin{array}{c}\text { Biovar } \\
3\end{array}$ & & $\begin{array}{c}\text { Biovar } \\
1\end{array}$ & $\begin{array}{c}\text { Biovar } \\
2\end{array}$ & & & \\
\hline Arginine hydrolysis & $+^{a}$ & + & + & + & + & + & + & - & - & + & - & + & - \\
\hline Esculin hydrolysis & + & - & + & + & + & + & + & - & - & - & + & + & + \\
\hline $\begin{array}{l}\text { Extracellular poly- } \\
\text { saccharide }\end{array}$ & + & + & + & + & + & + & d & $\mathrm{d}$ & - & - & + & - & + \\
\hline Acetoin (VP) & - & - & - & - & - & - & - & - & - & - & d & d & + \\
\hline \multicolumn{14}{|l|}{$\begin{array}{l}\text { Acid produced } \\
\text { from: }\end{array}$} \\
\hline Amygdalin & - & - & - & $\mathrm{d}$ & + & + & + & - & - & - & + & d & d \\
\hline Arbutin & $\mathrm{d}$ & + & + & + & + & + & + & - & - & - & + & + & + \\
\hline Melibiose & + & - & d & - & + & - & - & $t^{b}$ & $\mathrm{~d}$ & + & - & d & + \\
\hline Inulin & + & + & + & d & + & $\mathrm{d}$ & + & - & - & - & d & - & + \\
\hline Mannitol & - & - & - & - & - & - & - & - & - & - & - & - & + \\
\hline Sorbitol & - & - & d & - & - & - & - & - & - & $d$ & - & - & + \\
\hline Raffinose & + & - & d & - & + & - & - & $\mathrm{d}$ & d & + & - & $\mathrm{d}$ & + \\
\hline$\beta$-Glucosaminidase ${ }^{c}$ & - & - & - & - & + & + & + & + & - & + & - & d & - \\
\hline$\alpha$-L-Fucosidase ${ }^{d}$ & - & - & - & - & + & + & + & - & - & - & - & - & - \\
\hline Acid phosphatase $^{c}$ & + & - & - & + & + & + & + & $\mathrm{d}$ & d & + & $+^{b}$ & $\mathrm{~d}$ & $+^{b}$ \\
\hline $\begin{array}{l}\text { Alkaline phospha- } \\
\text { tase }^{c}\end{array}$ & $\mathrm{~d}^{b}$ & - & - & - & + & + & + & + & d & $\mathrm{d}$ & + & + & - \\
\hline IgA1 protease & + & + & + & + & - & - & - & + & d & - & - & - & - \\
\hline Neuraminidase & - & - & - & - & - & - & - & + & d & - & - & - & - \\
\hline
\end{tabular}

${ }^{a}+, 90 \%$ or more of the strains are positive;,$- 90 \%$ or more of the strains are negative; $d, 11$ to $89 \%$ of the strains are positive.

${ }^{b}$ Reactions are usually weak.

$c$ Determined with an API ZYM kit.

${ }^{d}$ Determined with an API ZYM osidase kit.

acid and rhamnose (10), and the peptidoglycan type is Lys-Ala $_{1-3}(30,41)$. Biochemical, physiological, and serological characteristics of the species and three biovars are shown in Table 3 . The $\mathrm{G}+\mathrm{C}$ content of the DNA is 40 to 43 mol\% (13). S. gordonii resembles $S$. sanguis but can be differentiated from this species by several biochemical characteristics (Tables 3 and 4), by a lack of IgA1 protease, and by a significantly different $\mathrm{G}+\mathrm{C}$ content. Found in human oral cavities and pharynges. The type strain is strain ATCC 10558 (= NCTC 7865). The reactions of the type strain are the majority reactions for $S$. gordonii biovar 2 given in Table 3. The $\mathrm{G}+\mathrm{C}$ content of the type strain is $41 \mathrm{~mol} \%$.

Emended description of Streptococcus sanguis White and Niven 1946, 722. Cells are gram positive and usually grow in short chains in serum broth. They are nonmotile, nonsporing, aerobic and facultatively anaerobic, fermentative, and catalase negative and show $\alpha$-hemolysis on horse blood agar and pronounced greening on chocolate agar. The cell wall contains glycerol teichoic acid and rhamnose (10), and the peptidoglycan type is Lys-Ala 1-3 $(30,41)$. Biochemical, physiological, and serological characteristics of the species and its biovars are shown in Table 3. Found in human mouths. The type strain is strain ATCC 10556 (= NCTC 7863). The reactions of the type strain are the majority reactions for $S$. sanguis biovar 1 given in Table 3, with the exceptions indicated. The $\mathrm{G}+\mathrm{C}$ content of the type strain is $46 \mathrm{~mol} \%$ (13).

Emended description of Streptococcus oralis Bridge and Sneath 1982, 414. Cells are gram-positive cocci and usually grow in long chains in serum broth. They are nonmotile, nonsporing, aerobic and facultatively anaerobic, fermentative, and catalase negative and show $\alpha$-hemolysis on horse blood agar and pronounced greening on chocolate agar. The cell wall contains ribitol teichoic acid and lacks significant amounts of rhamnose (10). The peptidoglycan type is Lysdirect $(30,41)$. Biochemical, physiological, and serological characteristics of the species are shown in Table 3. Contrary to information provided in previous descriptions $(2,30), S$. oralis does not have lysine decarboxylase activity, does not hydrolyze arginine or esculin, and is negative in the Voges-

TABLE 5. Correlation between the classification resulting from this study and designations used previously

\begin{tabular}{|c|c|c|c|c|c|c|c|}
\hline \multirow{2}{*}{$\begin{array}{l}\text { Taxon as defined } \\
\text { in this study }\end{array}$} & \multicolumn{7}{|c|}{ Designation used by: } \\
\hline & $\begin{array}{l}\text { Sherman } \\
\text { et al. }(41)^{a}\end{array}$ & $\begin{array}{l}\text { Carlsson } \\
\quad(5)\end{array}$ & $\begin{array}{l}\text { Colman and } \\
\text { Williams (11) }\end{array}$ & $\begin{array}{l}\text { Coykendall and } \\
\text { Specht (13) }\end{array}$ & Facklam (17) & $\begin{array}{l}\text { Hamada } \\
\text { et al. (23) }\end{array}$ & $\begin{array}{l}\text { Kilpper-Bälz } \\
\text { et al. (30) }\end{array}$ \\
\hline S. sanguis & Type I & $\mathrm{I}: \mathrm{B}$ & S. sanguis & $\begin{array}{l}\text { Genotype } 3 \text {, "S. sanguis } \\
\text { subsp. carlssonii"" }\end{array}$ & S. sanguis I & $\begin{array}{l}\text { Biotype A, } \\
\text { serotype I }\end{array}$ & S. sanguis \\
\hline S. gordonii & Type I-II & & S. sanguis & $\begin{array}{l}\text { Genotype } 1 \text {, "S. sanguis } \\
\text { subsp. sanguis" }\end{array}$ & S. sanguis I & $\begin{array}{l}\text { Biotype A, } \\
\text { serotype III }\end{array}$ & S. mitis \\
\hline S. oralis & Type II & I:A & "S. mitior" & Genotype $2, " S$. mitior" & S. sanguis II & $\begin{array}{l}\text { Biotype B, } \\
\text { serotype II }\end{array}$ & S. oralis \\
\hline S. mitis biovar 1 & & $\mathrm{~V}: \mathrm{A}$ & "S. mitior" & & S. mitis & & \\
\hline S. mitis biovar 2 & & $\mathrm{~V}: \mathrm{B}$ & "S. mitior" & & & & \\
\hline
\end{tabular}

\footnotetext{
${ }^{a}$ The numbers in parentheses are reference numbers.
} 
Proskauer reaction (acetoin). The $\mathrm{G}+\mathrm{C}$ content of the DNA is 39 to $42 \mathrm{~mol} \%$ (12). Found in human oral cavities. The type strain is strain NCTC 11427 . The characteristics of the type strain are the majority reactions for $S$. oralis given in Table 3 , with the exceptions indicated. The $\mathrm{G}+\mathrm{C}$ content of the type strain is $41 \mathrm{~mol} \%$.

Emended description of Streptococcus mitis Andrewes and Horder 1906, 712. Cells are gram-positive cocci and grow in short or long chains in serum broth. They are nonsporing, aerobic and facultatively anaerobic, nonmotile, fermentative, and catalase negative and show $\alpha$-hemolysis on horse blood agar and pronounced greening on chocolate agar. The cell wall contains ribitol teichoic acid and lacks significant amounts of rhamnose (10). The peptidoglycan type is Lysdirect $(30,41)$. Biochemical, physiological, and serological characteristics of the species and two biovars are shown in Table 3. The $\mathrm{G}+\mathrm{C}$ content of the DNA is 39 to $41 \mathrm{~mol} \%$ (12). Found in human mouths and pharynges. The type strain is strain NCTC 12261. The reactions of the type strain are the majority reactions for $S$. mitis biovar 1 given in Table 3 . The $\mathrm{G}+\mathrm{C}$ content of the type strain is $41 \mathrm{~mol} \%$.

\section{ACKNOWLEDGMENTS}

The technical help provided by Kirsten Holmgren and Ella Brandt and the secretarial assistance of Dorthe Eggertsen are gratefully acknowledged. Thanks are also due to Bente Nyvad for a critical review of the manuscript, to Jesper Reinholdt for help with one of the assays, and to several colleagues (see Table 1) for providing some of the strains used in the study.

\section{LITERATURE CITED}

1. Andrewes, F. W., and T. J. Horder. 1906. A study of the streptococci pathogenic for man. Lancet ii:708-713.

2. Bridge, P. D., and P. H. A. Sneath. 1982. Streptococcus gallinarum sp. nov. and Streptococcus oralis sp. nov. Int. J. Syst. Bacteriol. 32:410-415.

3. Bridge, P. D., and P. H. A. Sneath. 1983. Numerical taxonomy of Streptococcus. J. Gen. Microbiol. 129:565-597.

4. Carlsson, J. 1967. Presence of various types of nonhaemolytic streptococci in dental plaque and in other sites of the oral cavity in man. Odontol. Revy 18:55-74.

5. Carlsson, J. 1968. A numerical taxonomic study of human oral streptococci. Odontol. Revy 19:137-160.

6. Carisson, J. 1970. Chemically defined medium for growth of Streptococcus sanguis. Caries Res. 4:297-304.

7. Cole, R. M., G. B. Calandra, E. Huff, and K. M. Nugent. 1976. Attributes of potential utility in differentiating among "group H" streptococci or Streptococcus sanguis. J. Dent. Res. 55(Special Issue A):A142-A153.

8. Colman, G. 1968. The application of computers to the classification of streptococci. J. Gen. Microbiol. 50:149-158.

9. Colman, G., and L. C. Ball. 1984. Identification of streptococci in a medical laboratory. J. Appl. Bacteriol. 57:1-14.

10. Colman, G., and R. E. O. Williams. 1965. The cell walls of streptococci. J. Gen. Microbiol. 41:375-387.

11. Colman, G., and R. E. O. Williams. 1972. Taxonomy of some human viridans streptococci, p. 282-299. In L. W. Wannamaker and J. M. Matsen (ed.), Streptococci and streptococcal diseases. Academic Press, Inc., New York.

12. Coykendall, A. L., and A. J. Munzenmaier. 1978. Deoxyribonucleic acid base sequence studies on glucan-producing and glucan-negative strains of Streptococcus mitior. Int. J. Syst. Bacteriol. 28:511-515.

13. Coykendall, A. L., and P. A. Specht. 1975. DNA base sequence homologies among strains of Streptococcus sanguis. J. Gen. Microbiol. 91:92-98.

14. Coykendall, A. L., P. M. Wesbecher, and K. B. Gustafson. 1987. "Streptococcus milleri," Streptococcus constellatus, and
Streptococcus intermedius are later synonyms of Streptococcus anginosus. Int. J. Syst. Bacteriol. 37:222-228.

15. Drucker, D. B., and T. H. Melville. 1971. The classification of some oral streptococci of human and rat origin. Arch. Oral Biol. 16:845-853.

16. Edwardsson, S. 1968. Characteristics of caries-inducing streptococci resembling Streptococcus mutans. Arch. Oral Biol. 13: $637-646$.

17. Facklam, R. R. 1977. Physiological differentiation of viridans streptococci. J. Clin. Microbiol. 5:184-201.

18. Facklam, R. R. 1984. The major differences in the American and British streptococcus taxonomy schemes with special reference to Streptococcus milleri. Eur. J. Clin. Microbiol. 3:91-93.

19. Gibbons, R. J., and S. B. Banghart. 1967. Synthesis of extracellular dextran by cariogenic bacteria and its presence in human dental plaque. Arch. Oral Biol. 12:11-24.

20. Gilmour, M. N., T. S. Whittam, M. Kilian, and R. K. Selander. 1987. Genetic relationships among the oral streptococci. J. Bacteriol. 169:5247-5257.

21. Gordon, M. H. 1905. A ready method of differentiating streptococci and some results already obtained by its application. Lancet i: 1400-1403.

22. Guggenheim, B. 1968. Streptococci of dental plaques. Caries Res. 2:147-163.

23. Hamada, S., M. Torii, Y. Tsuchitani, and S. Kotani. 1980. Isolation and immunobiological classification of Streptococcus sanguis from human tooth surfaces. J. Clin. Microbiol. 12: 809-817.

24. Hardie, J. M. 1986. Oral streptococci, p. 1054-1063. In P. H. A. Sneath, N. S. Mair, M. E. Sharpe, and J. G. Holt (ed.), Bergey's manual of systematic bacteriology, vol. 2. The Williams \& Wilkins Co., Baltimore.

25. Hardie, J. M., R. A. Whiley, and M. J. Sakin. 1982. A numerical taxonomic study of oral streptococci, p. 59-60. In S. E. Holm and P. Christensen (ed.), Basic concepts of streptococci and streptococcal diseases. Reedbooks, Ltd., Surrey, United Kingdom.

26. Hehre, E. J., and J. M. Neill. 1946. Formation of serologically reactive dextran by streptococci from subacute bacterial endocarditis. J. Exp. Med. 83:147-162.

27. Kilian, M., and K. Holmgren. 1981. Ecology and nature of immunoglobulin Al protease-producing streptococci in the human oral cavity and pharynx. Infect. Immun. 31:868-873.

28. Kilian, M., L. Mikkelsen, and J. Henrichsen. 1989. Replacement of the type strain of Streptococcus mitis. Request for an Opinion under Rule 18g. Int. J. Syst. Bacteriol. 39:498-499.

29. Kilian, M., B. Nyvad, and L. Mikkelsen. 1986. Taxonomic and ecological aspects of some oral streptococci, p. 391-400. In S. Hamada, S. M. Michalek, H. Kiyono, L. Menaker, and J. R. McGhee (ed.), Molecular microbiology and immunobiology of Streptococcus mutans. Elsevier Science Publishing Co., Inc., New York.

30. Kilpper-Bälz, R., P. Wenzig, and K. H. Schleifer. 1985. Molecular relationships and classification of some viridans streptococci as Streptococcus oralis and emended description of Streptococcus oralis (Bridge and Sneath 1982). Int. J. Syst. Bacteriol. 35:482-488.

31. Kilpper-Bälz, R., B. L. Williams, R. Lutticken, and K. H. Schleifer. 1984. Relatedness of "Streptococcus milleri" with Streptococcus anginosus and Streptococcus constellatus. Syst. Appl. Microbiol. 5:494-500.

32. Lautrop, H. 1960. Laboratory diagnosis of whooping-cough or Bordetella infections. Bull. W.H.O. 23:15-31.

33. Mikkelsen, L., S. B. Jensen, and J. Jakobsen. 1981. Microbial studies on plaque from carious and caries-free proximal tooth surfaces in a population with high caries experience. Caries Res. 15:428-435.

34. Mizuno, J., M. Torii, T. Yamamoto, and S. Hamada. 1983. Detection of amphipathic antigen unique to biotype B Streptococcus sanguis. FEMS Microbiol. Lett. 16:209-212.

35. Møller, V. 1955. Simplified tests for some amino acid decarboxylases and for the arginine dihydrolase system. Acta Pathol. Microbiol. Scand. 36:158-172. 
36. Müller, H. E. 1984. ABTS perioxidase medium as a highly sensitive plate assay for detection of hydrogen peroxide production in bacteria. J. Microbiol. Methods 2:101-102.

37. Nyvad, B., and M. Kilian. 1987. Microbiology of the early colonization of human enamel and root surfaces in vivo. Scand. J. Dent. Res. 95:369-380.

38. Ottens, H., and K. R. Winkler. 1962. Indifferent and hemolytic streptococci possessing group antigen F. J. Gen. Microbiol. 28:181-191.

39. Rosan, B. 1978. Absence of glycerol teichoic acids in certain oral streptococci. Science 201:918-920.

40. Rosan, B. 1983. Antigens of Streptococcus sanguis. Infect. Immun. 7:205-211.

41. Schmidhuber, S., R. Kilpper-Bälz, and K. H. Schleifer. 1987. A taxonomic study of Streptococcus mitis, S. oralis, and $S$. sanguis. Syst. Appl. Microbiol. 10:74-77.

42. Sherman, J. M., C. F. Niven, Jr., and K. L. Smiley. 1943. Streptococcus salivarius and other non-hemolytic streptococci of the human throat. J. Bacteriol. 45:249-263.

43. Skerman, V. B. D., V. McGowan, and P. H. A. Sneath (ed.). 1980. Approved lists of bacterial names. Int. J. Syst. Bacteriol. 30:225-420.

44. Varki, A., and S. Diaz. 1983. A neuraminidase from Streptococ- cus sanguis that can release $O$-acetylated sialic acids. J. Biol. Chem. 258:12465-12471.

45. Waitkins, S. A., L. C. Ball, and C. A. M. Fraser. 1980. Use of the API-ZYM system in rapid identification of $\alpha$ and nonhaemolytic streptococci. J. Clin. Pathol. 33:53-57.

46. Washburn, M. R., J. C. White, and C. F. Niven, Jr. 1946. Streptococcus s.b.e.: immunological characteristics. J. Bacteriol. 51:723-729.

47. Welborn, P. P., W. K. Hadley, E. Newbrun, and D. M. Yajko. 1983. Characterization of strains of viridans streptococci by deoxyribonucleic acid hybridization and physiological tests. Int. J. Syst. Bacteriol. 33:293-299.

48. Whiley, R. A., and J. M. Hardie. 1988. Streptococcus vestibularis sp. nov. from the human oral cavity. Int. J. Syst. Bacteriol. 38:335-339.

49. Whiley, R. A., J. M. Hardie, and P. J. H. Jachman. 1982. SDS-polyacrylamide gel electrophoresis of oral streptococci, p. 61-62. In S. E. Holm and P. Christensen (ed.), Basic concepts of streptococci and streptococcal diseases. Reedbooks, Ltd., Surrey, United Kingdom.

50. White, J. C., and C. F. Niven, Jr. 1946. Streptococcus S.B.E.: a streptococcus associated with subacute bacterial endocarditis. J. Bacteriol. 51:717-722. 